\title{
Cultura, interculturalidade e processo saúde-doença: (des) caminhos na atenção à saúde dos Guarani Mbyá de Aracruz, Espírito Santo
}

| ${ }^{1}$ Luiz Henrique C. Pellon, ${ }^{2}$ Liliana A. Vargas |

Resumo: A ideia de elaborar este artigo surge como uma forma de sistematizar as reflexões suscitadas a partir da temática "Tensões interculturais e os impactos no processo saúde-doença na população Guarani Mbyá do município de Aracruz, Espírito Santo", abordada por seus autores, num processo de construção do conhecimento na pós-graduação em enfermagem da Universidade Federal do Estado do Rio de Janeiro. Dessa forma, o artigo se propõe a estimular uma reflexão sobre as contradições surgidas dentro da política de saúde indígena no Brasil, cujas normativas não conseguem, de fato, contribuir para a estruturação de novas abordagens que valorizem a diversidade do ponto de vista étnico e cultural. Sua metodologia pode ser tipificada como descritiva, com abordagem qualitativa, do tipo estudo de caso. Os dados foram coletados a partir de entrevistas semiestruturadas realizadas junto a representantes das comunidades Mbyá de Aracruz, Espírito Santo, estando sua análise apoiada nas propostas normativas que subsidiam as práticas de atenção à saúde indígena. Concluí-se que a atenção à saúde indígena costuma sofrer influências dos interesses políticos, econômicos e sociais locais, regionais e globais que em muitos aspectos se sobrepõem ou negligenciam aqueles aspectos indispensáveis à promoção e proteção da qualidade de vida dos Guarani Mbyá aldeados em Aracruz.

> Palavras-chave: enfermagem; processo saúde-doença; saúde indígena; políticas de saúde.

\author{
${ }^{1}$ Mestre em Enfermagem, \\ professor assistente do \\ Departamento de Enfermagem \\ de Saúde Pública da Escola \\ de Enfermagem Alfredo Pinto \\ da Universidade Federal do \\ Estado do Rio de Janeiro (EEAP/ \\ UNIRIO). Endereço eletrônico: \\ Ihpellon@globomail.com \\ ${ }^{2}$ Doutora em Saúde Coletiva, \\ professora adjunta do \\ Departamento de Enfermagem \\ de Saúde Pública da EEAPI \\ UNIRIO. Endereço eletrônico: \\ lilianaangel@globomail.com
}


O povo Guarani constitui um dos mais expressivos povos indígenas da América do Sul, perfazendo um contingente de aproximadamente 225 mil pessoas presentes em cinco países do continente. No Brasil, é representado por aproximadamente 50 mil índios distribuídos em três subgrupos, denominados: Mbyá (gente), Nandeva (os nossos) e Kaiowá (habitantes das matas), que vivem em cem municípios de dez estados das regiōes Sul, Sudeste e Centro-Oeste do país.

Os Guarani Mbyá circulam e habitam secularmente em áreas de Mata Atlântica em aldeias reconhecidas pelo poder estatal ou acampados à beira das estradas no interior e litoral das regiōes Sul e Sudeste, próximo aos maiores núcleos urbanos e industriais do país com os quais estabelecem relações de troca. Do ponto de vista lingüístico, são bilíngues, pois, apesar de falarem o dialeto Mbyá da língua Guarani, incluída na família linguística Tupi-Guarani, do tronco linguístico Tupi, também se comunicam nas línguas oficiais dos países em que habitam, ou seja, o português ou o espanhol.

É possível afirmar que a condição em que se encontram os Mbyá contemporâneos pode ser tomada como referência para se analisar os avanços e retrocessos das políticas indigenistas frente aos interesses econômicos nacionais e transnacionais que ameaçam a reprodução física e cultural dos povos indígenas do Brasil, pois a maioria dos grupos convive desde os primórdios da colonização com a desenfreada urbanização e industrialização dos espaços geográficos que reconhecem como parte de seu território sagrado.

Considerando que "a política deveria ser (e é, ainda que não consigamos apreciar este fato) ponto de criação e de regulação de autonomia” (CAMPOS; CAMPOS, 2006, p. 674) pautaremos nossa reflexão nas contradições surgidas dentro da política de saúde indígena do Brasil, cujas normativas não conseguiram promover, ainda, a consolidação de abordagens que valorizem a diversidade de interpretações e modos de intervenção na área da saúde segundo critérios de etnicidade e cultura.

\section{Metodologia}

Este artigo resulta de uma pesquisa descritiva com abordagem qualitativa do tipo estudo de caso, cujos objetivos foram identificar a noção de cultura dos Guarani Mbya e analisar as tensões interculturais que surgem a partir do atendimento aos membros dessa comunidade na rede de serviços de saúde local. 
A pesquisa foi desenvolvida entre os anos 2006 e 2008 nas aldeias Três Palmeiras, Piraquê-Açu Mirim e Boa Esperança, no município de Aracruz, Espírito Santo, que possuíam um contingente populacional em torno de 250 habitantes. Como estratégia para a coleta dos dados, adotou-se a entrevista semiestruturada gravada com professores, agentes indígenas de saúde e lideranças sociais (caciques e vice-caciques) e religiosas (anciãos e pajés). A utilização desta técnica teve como proposta oferecer subsídios para a análise das relações interculturais na atenção à saúde a partir da fala de membros do grupo que, no exercício de sua função social e política, "transitavam" cotidianamente nos espaços interculturais de negociação e defesa dos interesses indígenas.

Portanto, foram selecionados relatos de depoentes que representam as ideias centrais apontadas pelos sujeitos da pesquisa acerca do atendimento às necessidades de saúde nos espaços sociais e institucionais. Visando a distinguir ambos os entrevistados considerando-se os critérios de anonimato nas identificações, os sujeitos selecionados foram representados textualmente como Professor, Liderança A e Liderança B.

Como suporte metodológico para tratamento dos dados, foi utilizado o método de análise de conteúdo, descrito por Turato (2003). A concepção de signo ideológico postulada por Bakhtin, que trata a "linguagem como espaço de recuperação do sujeito como ser histórico e social” (SOUZA, 2001, p. 93) serviu como suporte teórico para a leitura dos relatos dos sujeitos da pesquisa. Para análise dos dados, foram contemplados os documentos nacionais e internacionais que fazem referência aos princípios normativos necessários à redução e/ou erradicação da situação de desigualdade de acesso aos bens e serviços essenciais à promoção e proteção da qualidade de vida e saúde dos povos indígenas.

A pesquisa que deu origem a este artigo foi submetida à apreciação do Comitê de Ética em Pesquisa (CEP) da UNIRIO, à Comissão Nacional de Ética em Pesquisa (CONEP), ao Conselho Nacional de Desenvolvimento Científico e Tecnológico (CNPq) e à Fundação Nacional do Índio (FUNAI), para avaliação, que tomou como base os princípios éticos contidos nas Resoluções CNS nº 196/1996 e CNS n 304/2000. A Autorização para Ingresso em Terra Indígena CGEP/FUNAI no 30/2007 foi concedida após as avaliações cabíveis e a formalização da anuência das respectivas lideranças indígenas.

A seguir, será descrita uma breve abordagem acerca da Política Nacional de Atenção à Saúde dos Povos Indígenas do Brasil, com vistas a conferir um suporte teórico para a reflexão proposta. 


\section{Política indigenista de saúde no Brasil}

A atenção à saúde dos povos indígenas do Brasil tem sido historicamente marcada pela intermitência, desarticulação e imposição do caráter assimilacionista dos valores ocidentais aos índios e suas culturas, amplamente adotado pelas políticas públicas que precederam a abertura democrática do país.

Após o advento da República, o assimilacionismo, amplamente adotado pelos grupos religiosos durante o colonialismo, assumiu uma nova roupagem: o positivismo, que deu continuidade ao projeto de erradicação das diferenças culturais através da padronização da sociedade brasileira segundo seus moldes sociais. Se por um lado, as estratégias positivistas viabilizaram a aproximação das lideranças indígenas com a lógica da organização política da sociedade ocidental, por outro, facilitaram às lideranças indígenas se apropriarem dos mecanismos ideológicos de luta pela conquista do espaço público para defesa dos direitos étnicos diferenciados no campo da saúde e da educação.

$\mathrm{Na}$ década de 1980, o país passou por amplo processo de reestruturação do modelo de intervenção estatal na área social, criando condições propícias à emergência de um movimento organizado voltado a discutir e promover uma reforma no modelo sanitário vigente. As diretrizes propostas por este movimento, denominado Movimento pela Reforma Sanitária, foram descritas em pormenores na VIII Conferência Nacional de Saúde, realizada no ano de 1986, e contemplavam a construção de um sistema de saúde, unificado, descentralizado, com acesso universal e atendimento integral. Existe amplo consenso de que o conceito ampliado de saúde definido no relatório final da respectiva conferência constituiu o alicerce sobre o qual se tornou possível construir a proposta política e organizacional do atual Sistema Único de Saúde (SUS), pois, ao considerarmos sua abrangência conceitual, percebemos que estamos lidando com a própria noção de vida (BUSS, 2003), ou mesmo com os elementos necessários ao desenvolvimento da vida com qualidade e dignidade.

Como imperativo ao processo de ampliação das responsabilidades estatais com a universalidade do acesso aos serviços de atenção à saúde, tornou-se necessário discutir, então, a construção de um subsistema voltado ao atendimento das especificidades sanitárias dos povos indígenas do país, marcada pela situação histórica de penúria e abandono. Foi dessa forma que, no bojo da VIII Conferência Nacional de Saúde, aconteceu a I Conferência Nacional de Proteção à Saúde do 
Índio, com ampla adesão e participação do Movimento Indígena Organizado e dos representantes das várias etnias que habitavam o território nacional. Nela foi proposta a implantação de um modelo de atenção à saúde que deveria garantir a universalidade e a integralidade das suas ações, a transferência da responsabilidade oficial da prestação de serviços para o Ministério da Saúde, ${ }^{1}$ a ênfase no respeito às diferenças étnico-culturais de cada povo e maior representatividade dos índios por meio da participação e do controle social.

Em 1988, o texto constitucional definiu, em dois de seus artigos, ${ }^{2}$ o compromisso da União com o reconhecimento das organizações sociais indígenas, costumes, línguas, crenças e tradiçōes, e com os direitos originários sobre as terras que tradicionalmente ocupam, garantindo aos índios, também, o direito de ingressar em juízo pela defesa dos seus direitos, tornando obsoleta a função de tutela vigente até o momento. A abordagem constitucional da saúde como direito universal relacionado a seus determinantes e condicionantes sociais e econômicos possibilitou que os componentes da etnicidade de cada povo passassem a ser contemplados, pelo menos normativamente, como elementos essenciais à manutenção da vida com qualidade.

Em 1993, a II Conferência Nacional de Saúde do Índio formatou o modelo do Subsistema Diferenciado de Atenção à Saúde Indígena, baseado na figura dos Distritos Sanitários Especiais Indígenas (DSEI), dos Conselhos Distritais e da participação paritária dos usuários nos mesmos. O DSEI é conceitualmente descrito como um modelo operacional de serviços que integra a lógica da descentralização, regionalização e hierarquização dos serviços em espaços populacionais, geográficos, sociais, etnológicos, culturais e administrativos bem definidos ${ }^{3}$ (BRASIL, 2002). Apesar da formatação do modelo distrital em meados da década de 1990, foi somente em 1999 que ganhou fôlego no Ministério da Saúde, sob o encargo da Fundação Nacional de Saúde (FUNASA), a responsabilidade pela criação do subsistema, organizado em 34 DSEIs.

A construção do Subsistema de Atenção à Saúde Indígena ocorreu, no entanto, em um momento em que a descentralização do SUS estava sendo consolidada e os setores envolvidos neste processo trabalhavam incessantemente para transferir as atribuições da esfera federal para as Secretarias Municipais de Saúde. A opção política pela manutenção de um órgão do governo federal na função de gestor e executor do subsistema gerou uma contradição com a proposta de organização 
do SUS. A opção encontrada pelos dirigentes da FUNASA para viabilizar a concretização de atividades sanitárias nas aldeias foi a terceirização da assistência, celebrada através de convênios com as prefeituras locais, que passaram a assumir a totalidade das atividades de atenção à saúde indígena (GARNELO, 2004).

Em 2006, foi realizada a IV Conferência Nacional de Saúde Indígena, tendo como tema central, "Distrito Sanitário Especial Indígena: território de produção de saúde, proteção da vida e valorização das tradições”. A conferência teve cinco eixos temáticos de discussão, a saber: direito à saúde; controle social e gestão participativa; desafios indígenas atuais; trabalhadores indígenas e não indígenas em saúde e segurança alimentar, nutricional e desenvolvimento sustentável. A grande representatividade dos conselhos indígenas nessa conferência foi percebida como um avanço nos coeficientes de autonomia e empoderamento desses povos. Contudo, a persistência de uma precária situação de saúde entre os povos originários do país ocupou grande parte das discussóes na busca por encontrar interfaces para uma melhor qualificação dos serviços e para a diminuição dos elevados níveis de morbimortalidade indígena, que ainda hoje se igualam e, em muitos casos, superam os dos segmentos mais empobrecidos da sociedade brasileira.

Mais de duas décadas se passaram desde a Primeira Conferência Nacional de Saúde Indígena e o modelo de atenção à saúde tem constituído, contudo, objeto da mais variada sorte de denúncias e contestaçōes por parte dos representantes dos povos indígenas e seus aliados políticos devido às influências dos interesses econômicos locais, regionais e globais que se interpóem à qualidade do gerenciamento dos serviços nos âmbitos municipais. Dessa forma, analisar as situações que emergem a partir do encontro entre os interesses dos diferentes segmentos populacionais que coabitam um mesmo espaço territorial revela uma perspectiva ampliada da pesquisa em saúde pública, onde se faz mister a ampliação, também, de conceitos como saúde/doença e cultura, numa perspectiva inter e transdiciplinar que permita a estruturação de uma política de saúde indígena mais includente e resolutiva, pautada no respeito à diferença e à pluralidade.

A seguir, serão apresentados os resultados agrupados em três categorias que foram criadas segundo o critério de relevância temática para a reflexão proposta neste artigo. Os dados revelam que os conceitos de saúde e de doença não representam a mesma coisa para todas as pessoas, pois, de acordo com Scliar (2007), dependem da época, do lugar, da conjuntura social, econômica, política e 
cultural. No caso dos Mbyá de Aracruz, eles expressam, também, que a qualidade do atendimento nos serviços assistenciais é avaliada a partir de uma multiplicidade de fatores que transcendem a capacidade de oferta de recursos e tecnologias por parte dos órgãos governamentais, sendo influenciada principalmente pela qualidade das relações interpessoais que, também, são interculturais.

\section{Cultura, identidade e interculturalidade entre os Guarani Mbyá de Aracruz}

Para os Mbyá, a abundância de recursos hídricos, animais, frutos silvestres e plantas medicinais constitui o principal critério a ser observado para a escolha de um local onde se pretende fundar uma aldeia, por remontar as condições existentes em Yvy Mara Ey (Terra Sem Males), paraíso espiritual onde a doença e a morte são inexistentes. $\mathrm{Na}$ busca por tal espaço físico que possibilite o desenvolvimento da vida social baseada nos fundamentos culturais e espirituais milenares, os Mbyá refazem os caminhos já percorridos por seus antepassados e ocupam os lugares onde eles viveram, pois os consideram locais sagrados a serem retomados por seus contemporâneos com a finalidade de proteger as bases simbólicas que dão sustentação à vida humana no planeta.

Motivado por este ideal, após 40 anos de caminhada sob a condução de líderes religiosos de grande proeminência entre esse povo, um pequeno grupo Mbyá vindo do sul do país alcançou e se fixou na década de 1960 em uma área de Mata Atlântica no município de Aracruz, no Espírito Santo, onde já habitavam remanescentes do povo Tupiniquim. Pouco tempo após se instalarem na região, grande parte da Terra Indígena ${ }^{4}$ foi invadida, desmatada e transformada em monocultura de eucalipto pela maior empresa branqueadora de celulose do mundo. Os Mbyá viveram estas últimas quatro décadas sob forte confinamento fundiário em uma região onde se situam atualmente seis distritos urbanos, três rodovias estaduais e a empresa transnacional, que integra um complexo fabril às extensas áreas de monocultura de eucalipto e um porto marítimo voltado à exportação de seus produtos. Neste período os conflitos e tensões oriundos dos embates fundiários, passaram gradativamente da esfera política à social, imbricando-se nos relacionamentos entre povos indígenas, população regional e trabalhadores vinculados à companhia que dividiam os mesmos espaços públicos na busca por serviços essenciais à manutenção da qualidade de vida, entre os quais, os de atenção à saúde. 
Atualmente, a busca pela inversão do quadro histórico de desigualdade social, acentuado cada vez mais pela reestruturação neoliberal dos mercados e pelo modelo social globalizado, tem impulsionado os Mbyá de Aracruz e de outras regiōes a se apropriarem de novas tecnologias e recursos sem abrir mão de garantir e defender aquilo que consideram inegociável em sua cultura. Tal exemplo de expressão intercultural tem servido de referência para pesquisadores de diferentes áreas do conhecimento que buscam extrair da lógica do sistema relacional Mbyá as bases para a construção de modelos sociais centrados na superação das ideologias universalizantes e na circulação equânime de conhecimentos, recursos e tecnologias oriundos da natural rede de entrelaçamento entre os povos nas sociedades multiculturais.

A interculturalidade, entendida como a confrontação e o entrelaçamento que sucede quando os grupos entram em relaçôes de trocas (CACLINI, 2005), pressupõe conflitos, pois as culturas se desenvolvem na tensão, muitas vezes na violência, e só existem se produzidas por indivíduos ou grupos que ocupam posiçôes desiguais no campo social, econômico e político. É fato que as culturas se encontram em maior ou menor posição de força umas em relação às outras, mas é preciso evitar as interpretações reducionistas que supõem que o mais fraco está sempre sujeito a assimilar passivamente os valores e condiçõos impostos pelo mais forte no "jogo cultural" (CUCHE, 2002).

Embora não seja possível afirmar, no caso dos Mbyá aldeados em Aracruz, que o processo saúde-doença sofra influências unicamente das relações interculturais conflituosas, é importante destacar que o conhecimento das suas expressões no âmbito dos serviços de saúde e demais instituiçôes públicas pode contribuir para o delineamento de práticas voltadas ao comprometimento com a melhoria da qualidade de vida da população assistida, pois "nem sempre as mudanças que julgamos necessárias e imprescindíveis para a melhoria das condiçôes de vida de nossos clientes coincidem com os desejos e com a visão de mundo dessas pessoas" (SABOIA, 2003, p. 120).

Portanto, é no âmbito das instituições com as quais os Mbyá se relacionam atualmente que se é possível compreender a forma como as relações interculturais são determinadas hierarquicamente em função dos interesses sociais distintos. A noção de signo ideológico fornece os subsídios teóricos necessários à compreensão 
dos enunciados dos sujeitos da pesquisa sobre o atendimento prestado nesses espaços, pois todo elemento que possibilita expressar a ideologia de um determinado grupo social pode ser considerado como um signo. Entretanto, todo signo ideológico tem duas faces que permitem entendê-lo como uma arena onde se confrontam valores sociais e culturais contraditórios. Os signos não existem como parte de uma realidade única e dissociável do contexto de outros signos, pois refletem e retratam uma realidade na qual as ideologias se constroem no diálogo, ora refutando, ora refletindo outras realidades que lhes dão sentido. Assim, só é possível se compreender os signos através de outros signos (BAKHTIN, 2006).

É notório, portanto, que os enunciados dos Guarani contemporâneos abordem com certa frequência os valores que ordenam as práticas das instituições ocidentais de ensino, saúde, trabalho, religião e lazer com as quais se relacionam historicamente, estipulando comparações com outros signos na busca de evidenciar contrastes e conflitos dentro do seu próprio corpo social, em função de experimentarem de diferentes maneiras as relações interculturais. Dessa forma, é natural que o binômio cultura-identidade seja abordado unanimemente nos relatos a respeito das interações estipuladas com estes signos, mas sob a luz das fronteiras estipuladas para garantir a manutenção dos "marcos" de diferenciação étnica. E necessário ressaltar, no entanto, que as fronteiras colocadas nos relacionamentos entre os povos não devem ser encaradas como fator de isolamento, mas acima de tudo, como a possibilidade real de se relacionar preservando aspectos essenciais da sua cultura e identidade (BARTH, 1998).

Em pleno acordo com este pressuposto, os Mbyá aldeados em Aracruz sinalizaram que o estreitamento das relações dos sujeitos com as instituições e serviços é determinado não somente pela sua capacidade (ou incapacidade) de ofertar recursos e tecnologias imprescindíveis à melhoria da sua qualidade de vida e saúde, mas acima de tudo, pela possibilidade concreta de, enquanto espaços públicos, conciliar interesses sociais distintos para o fortalecimento dos coeficientes de autonomia e empoderamento social através da coparticipação no planejamento, execução e avaliação das atividades desenvolvidas nessas instituições.

Na próxima categoria, será abordada a relação entre os elementos constitutivos da etnicidade Mbyá e suas influências no pensamento dos seus representantes sobre as necessidades reconhecidas como prioritárias para a saúde individual e coletiva. 
Língua e religião Mbyá:

\section{identidade, pertencimento e saúde}

Ao tomarmos o signo como a arena das tensões interculturais, é possível nos reportarmos à ideia de dinamicidade cultural que permite que as culturas se desenvolvam através da mobilidade, da interação, do contato, da informação e da circulação de saberes e tecnologias que se dão consequentemente, mediadas pelas fronteiras estipuladas por cada povo nos relacionamentos com outros povos, conforme já abordado. Dessa forma, a refração do outro e dos seus valores por meio dos signos não deve ser tomada como uma analogia às teorias puristas que apregoavam que a preservação das culturas e das identidades indígenas só era possível através da indiferença hostil entre os índios e seus vizinhos. Ela é marca dos relacionamentos interculturais, onde as tensões se desenvolvem devido à nãoobservação dos limites da permeabilidade cultural, responsáveis por demarcar as barreiras intransponíveis que demarcam a preservação da identidade e da coesão social. Em pleno acordo com essa abordagem, um depoente relata que,

Cada cultura, ele tem sua cultura diferente. Então como é a vivência também, nós não pode viver assim como os branco. A gente fala, poder usar roupa dos branco, mas é que a língua e a vivência e seu religião, não pode esquecer do seu religião. Dança espiritual, então aí ele tem saúde, traz saúde para os filhos, traz saúde para as crianças, para as comunidade. (Liderança A)..

Se a língua e a religião constituem os elementos nucleares na formação e afirmação da identidade Mbyá, são também elementos que demarcam o campo do pertencimento, pois através delas os membros do grupo reconhecem seus pares distribuídos no vasto território Guarani. Assim, é possível ampliar a compreensão sobre a abordagem já feita pela liderança Mbyá nas palavras de outro depoente quando afirma:

Religião é uma coisa que fala muito da saúde, né. E a cultura também. Tudo vem junto. Mas primeiro você tem que se sentir bem pra caminhar sempre na direção certa pra não se perder no meio. Quando você perde totalmente seu costume, sua religião, você não sabe por onde caminhar. Aí você acha um bloqueio no seu caminho. Aí você não consegue se identificar mais e aí você se perde. E para você se sentir bem tem que ser sempre assim, procurando as regras do seu costume, as regras da sua religião, da sua cultura, como é que é. Eu acho que isso é saúde pra mim. Os conflito assim, às vezes acontece. É no caso de lá de Mato Groso do Sul. E bem, isso mesmo, que eles perderam totalmente a identidade e eles ficaram sem rumo, sem nada e aí eles viram índio contra índio. Tem que tomar muito cuidado, porque é que nem na entrada da igreja. Isso eu não queria falar mas isso prejudica muito, né. Eu sempre falo assim, 
igreja é assim, crente é coisa do jurua. Que eles também tem sua religião, eles esco-

lheram pra ser assim. Então, mas a gente, nós já temos a nossa religião, né. Pra que ter mais outra? Se aceitar tudo que vem de fora com certeza isso vai atingindo os mais novos. E aí quem atinge é os mais jovens, porque os mais velhos já tem a sua própria história, sua própria religião. (Professor).

É importante destacar que a língua e a religião são os elementos unificadores da sociedade Mbyá e é através deles, também, que os índios encontram explicações sobre os métodos milenares de promoção, proteção e recuperação da saúde. Por este motivo, a perda do vínculo com a religião autóctone constitui grande ameaça à preservação da identidade Mbyá e se apresenta como a condição primordial para a determinação dos processos mórbidos. A não-observância dos preceitos religiosos por grande parte dos membros de um grupo, no entanto, justifica o distanciamento das referências milenares de convívio entre os indivíduos, possibilitando que as tensões oriundas deste processo determinem a transição da doença da dimensão individual para a social, trazendo consequências drásticas para todo o grupo.

As interações com os representantes de outras religiões podem assumir formas distintas de acordo com os interesses envolvidos, como foi possível observar na aldeia Três Palmeiras, onde, para a construção de uma nova opy (casa de reza), os índios receberam fortes incentivos financeiros de missionários católicos com os quais mantinham relacionamentos duradouros e bem consolidados. Contrapondo-se a este modelo de relacionamento, representantes de uma igreja pentecostal vinham edificando seu templo bem próximo a esta opy, demonstrando que existia certa imprecisão na forma como se davam as relações entre pequena parcela da população e os adeptos dessa religião. É preciso ressaltar que a presença das igrejas pentecostais nas aldeias afronta o modo de ser Guarani, pois impõe estrategicamente sua modificação através de mecanismos de persuasão voltados à desconstrução das referências linguísticas, culturais e identitárias que demarcam o campo simbólico do pertencimento étnico.

Ficou patente, no entanto, que a aceitação do que lhes é oferecido em termos de edificação pelos agentes de outras religiōes e organizações com as quais se relacionam, assume uma ideologia que permite aos Mbyá entender o ganho material como parte do pagamento da dívida histórica contraída pelos nãoíndios com a sua sociedade. Assim, a oferta de alimentos se mostrou, também, como uma importante moeda de troca para garantir a presença nas celebrações ecumênicas, sobretudo das famílias expostas a maiores coeficientes de 
vulnerabilidade socioeconômica. Apesar de exercerem influências simbólicas reconhecidamente daninhas à coesão do grupo, os ritos pentecostais não costumavam mobilizar um grande quantitativo de pessoas nas aldeias capixabas, muitas das quais ainda se deslocavam para o ritual noturno (porahei) na opy (casa de reza) após o término dessas celebraçōes.

Faz-se mister observar as contradições existentes entre a ideologia institucional das igrejas pentecostais que adentram nas aldeias indígenas aproveitando-se das lacunas deixadas pela ausência do poder público e o disposto no artigo $5^{\circ} \mathrm{da}$ Convenção 169 da Organização Internacional do Trabalho (1989, p. 4), que dispõe que "deverão ser reconhecidos e protegidos os valores e práticas sociais, culturais e religiosos e espirituais próprios dos povos mencionados e deverse-á levar na devida consideração a natureza dos problemas que lhes sejam apresentados, tanto coletiva como individualmente."

As propostas normativas existentes atualmente permitem estabelecer uma ideologia de relacionamento intercultural para além da continuidade do projeto colonialista que encontra no vácuo deixado pela falta de efetivação das políticas sociais abrangentes as condiçôes propícias à sua continuidade e/ou reemergência. Contudo, faz-se necessário, ainda, ressoar as vozes emudecidas pela influência ideológica dominante, amplamente determinada pelos representantes das instituições que ocupam as lacunas deixadas pela carência dos múltiplos elementos determinantes e condicionantes de qualidade de vida e saúde nas sociedades indígenas. Investir na promoção das condições necessárias para que os índios possam fazer escolhas críticas, reflexivas e conscientes parece tratar-se do método mais adequado para superar sua anulação histórica enquanto sujeito de direitos.

$\mathrm{Na}$ próxima categoria, serão abordadas as relações no serviço hospitalar de referência para o atendimento aos Mbyá de Aracruz e as contradiçôes existentes para a consolidação de um subsistema que se apoia no paradigma da interculturalidade para o atendimento à população indígena do país.

\section{Interculturalidade e atenção diferenciada: uma trajetória de tensões}

A prática cultural recomenda que a doença seja diagnosticada dentro da opy (casa de reza) pelo Karai (xamã) que deve indicar o tratamento adequado, não se privando de encaminhar o paciente para o sistema público de atenção à saúde 
se assim julgar necessário. Inegavelmente, os Mbyá reconhecem que o contato secular com o homem branco produziu manifestações patológicas para as quais a medicina autóctone não dispõe de métodos eficazes, o que tem impulsionado a busca por intercâmbios viáveis para a resolução desses problemas.

Se por um lado, o modelo biomédico constitui um recurso indispensável atualmente, pareceu ser mais utilizado pelos Mbyá para o tratamento dos sintomas de algumas doenças, ao passo que as terapias autóctones geralmente eram direcionadas à etiologia dos processos mórbidos, ou seja, às suas causas, fossem elas, biológicas, espirituais ou sociais. Como parte integrante da sua cultura, o arcabouço terapêutico Mbyá não é estanque, cristalizado e parado no tempo, imune às transformações e ao diálogo com os outros sistemas de saúde. E muito comum os índios reconhecerem a eficácia do modelo biomédico e utilizarem-no para estipularem uma relação de complementaridade com os métodos autóctones, conforme foi possível identificar na fala de um depoente:

\begin{abstract}
A gente sempre tem esse costume assim, quando uma pessoa tá doente, então, primeiramente é consultado pelo pajé. Então aí, depois se no caso a pessoa tiver a doença assim que deveria ser tratado lá fora, o pajé também sabe. Então algumas pessoas que trabalha na saúde com os povos Guarani, aí eles não pode tá chegando e falar assim: 'você tem que ir pro médico direto'. Porque às vezes muitos casos já aconteceu aqui. Às vezes a pessoa leva e encaminha diretamente pra o hospital e às vezes os próprios médico não sabe o que é. Então com isso, às vezes até a gente tem essas falha com isso. (Liderança B).
\end{abstract}

Existem diferentes qualidades de Karai (xamã), que possuem conhecimentos específicos em cada campo do saber medicinal Guarani Mbyá, o que demanda, muitas vezes, a superação de obstáculos de ordem política e financeira para buscálos em outros estados quando se faz necessário. É importante destacar que os índios relataram encontrar enorme dificuldade em se fazer entender pelos gestores dos serviços públicos de saúde para a inclusão dessas despesas no orçamento da atenção diferenciada, pois, destacaram que os mesmos costumam considerar esses líderes religiosos de forma genérica, sem compreender a especificidade de cada um na arte de promover, proteger e/ou recuperar a saúde, assim como compreendem as diferentes especialidades do modelo biomédico. Os Guarani, com muitos esforços, quando conseguiam, se mobilizavam financeiramente para trazer essas lideranças para tratar algum enfermo necessitado ou, até mesmo, para a realização do importante ritual do neemongarai (batizado) uma vez ao ano, na época da colheita do milho verde. 
Alguns estudos (BERTOLANI, 2008; CICCARONE, 2001; PELLON, 2005; VEIGA, 2004) são unânimes em apontar uma insatisfação dos indígenas com relação ao atendimento dispensado no hospital da rede referenciada do SUS, em função de experimentarem situações de preconceito e etnocentrismo por parte dos profissionais e da população local, que dividem física e simbolicamente este espaço na busca pelo atendimento às suas necessidades de saúde. A opinião de um dos diretores técnicos do hospital de que os índios gozariam de um atendimento "privilegiado" ao invés de "diferenciado" (VEIGA, 2004) era materializada nas atitudes dos profissionais que atuavam nessa instituição e retomada no sentimento de discriminação contido no enunciado dos depoentes, conforme o de uma liderança Mbyá, ao afirmar que "o pessoal lá não atende os índio direito, eles são jogado [sic] fora e ainda xinga, é mole?” (PELLON, 2005, p. 54). Ainda segundo o mesmo diretor, "o índio acha que pode tudo e não gosta de esperar pelo atendimento" (VEIGA, 2004). Em um estudo antropológico sobre os Guarani de Aracruz, a autora sinalizou que "[...] na internação legitimavase a tentativa de transfiguração dos Mbyá da condição de grupo culturalmente distinto para o status genérico de cidadãos carentes com direito perversamente adquirido a um tratamento sanitário precário, agressivo, quando não etnocida” (CICCARONE, 2001, p. 58).

É importante sinalar que as formas como as discriminações se expressam nem sempre são tão evidentes, pois não raramente estão imiscuídas subliminarmente nas teias de relaçôes sociais e econômicas que estruturam e determinam a expressão do processo saúde-doença, seja de seus determinantes diretos como dos indiretos. Entretanto, vivenciar situações de discriminação pode ser por si só um elemento desencadeador de doenças e torna-se mais grave quando a experiência se passa dentro dos serviços de atenção a saúde, pois pode gerar fortes emoções, que vão do medo e desconfiança à raiva e frustração, comprometendo não somente a qualidade e a credibilidade dos serviços prestados, mas a própria saúde do indivíduo (COIMBRA JR.; SANTOS, 2000).

Os impactos da imposição de um modelo assistencial que universaliza e padroniza as práticas unicamente em função de regulamentos e protocolos, desconsiderando a influência cultural nas formas de se comportar diante da enfermidade, também merece considerações, pois vem sendo registrado em diferentes momentos da permanência dos Mbyá na região. O relato da matriarca 
da aldeia Boa Esperança, feito em 1994 (CICCARONE, 2001, p. 58), descrevendo que "naquele lugar você entra vivo e sai morto", é ilustrativo de tal situação. Mais de uma década se passou desde este triste lamento e suas palavras foram renovadas no enunciado de um sujeito da pesquisa ao reportar sua percepção sobre as condições que envolveram o falecimento de um membro da sua família.

Segundo ele, "os médico quando vê que espírito que está triste e ele não sabe, então ele aplica injeção pra..., às vezes aí piorou, às vezes dá a injeção pra matar ele" (Liderança A). O depoimento desta liderança evidencia claramente a dúvida, a desconfiança e o descrédito institucional como retrato de uma trajetória histórica marcada por situações de conflitos e tensões nas relações estipuladas entre índios, profissionais, técnicos e gestores da área da saúde.

Os enunciados dos sujeitos da pesquisa sobre o trabalho desenvolvido no hospital de referência, de uma forma geral, foram pontuados pela alusão a erros diagnósticos e terapêuticos e pela falta de compreensão, por parte dos profissionais, sobre os problemas que acometiam a alma dos indivíduos e determinavam o agravamento das enfermidades de cunho espiritual. Esta crítica era, portanto, constantemente acrescida de outra sobre a própria condição em que se encontravam, ou seja, a extrema dependência dos serviços públicos de saúde se encontrava intimamente associada ao processo de deterioração dos recursos naturais indispensáveis à manutenção da qualidade de vida, segundo os princípios culturais milenares.

O desconhecimento do diagnóstico da maioria dos índios que ia a óbito neste nosocômio foi descrito como um fato comum e observado com preocupação pelas lideranças indígenas que costumavam atribuir sua causa não somente aos problemas de interlocução com os representantes do sistema público de saúde, mas também à transgressão da norma cultural que recomenda a apresentação dos doentes primeiramente ao Karai (xamã), sem o qual se corre o risco de tratar erroneamente uma enfermidade de etiologia espiritual no âmbito hospitalar, onde para esta categoria de doença não existe tratamento.

É importante assinalar que, no pensamento autóctone, designado genericamente pela Antropologia Clássica como mágico-religioso, destacam-se tipos de males nãoequiparáveis às doenças ocidentais, quando o adoecimento é visto apenas como um aspecto de uma categoria mais ampla onde também se incluem a morte, o azar, os acidentes, o feitiço, o mau-olhado e outras desgraças (LUZ, 2005). 
À luz das considerações feitas pelos depoentes, ao adentrarem no hospital os sujeitos eram despidos de suas histórias de vida, de seus vínculos sociais e dos fatores culturais que podiam contribuir para gerar maiores coeficientes de autonomia e corresponsabilização entre ambas as partes envolvidas no processo terapêutico. Esta situação, vivenciada no âmbito dos serviços de saúde, contrasta com a lógica dos tratamentos realizados no sistema autóctone Mbyá, no qual a valorização e a participação do indivíduo como sujeito do seu cuidado constituem parte fundamental das práticas de atenção à saúde.

Um dos aspectos a serem considerados na atenção à saúde indígena diz respeito à incapacidade do poder municipal atender condignamente às necessidades dos índios, pois, frequentemente, os grupos indígenas são precariamente tolerados, ou mesmo ostensivamente rechaçados pela população local, em decorrência de atitudes etnocêntricas e disputas fundiárias que ocorrem habitualmente (CONFALONIERI, 1993). Assim, após a revogação da Portaria MS $\mathrm{n}^{\circ}$ 2656/2007 (BRASIL, 2007), que reforçou o processo de descentralização das açôes de atenção à saúde indígena para os sistemas municipais de saúde, as lideranças Mbyá estavam temerosas de que a falta de capacitação intercultural dos profissionais da rede pública, aliada ao comprometimento social com os interesses econômicos da transnacional, favorecessem a continuidade da baixa qualidade dos serviços prestados.

No universo dinâmico dos relacionamentos interculturais contemporâneos, entretanto, a abordagem do processo saúde-doença implica um encontro de duas ou mais visões sobre as possíveis soluções para os problemas de saúde que partem de marcos contextuais distintos, exigindo uma mudança nos paradigmas que leve a uma análise não desde a visão biomédica, mas desde aquela gerada através da sensibilidade e respeito à diferença e fundamentada no princípio básico da vida (OMS/OPAS, 1998). Em pleno acordo com essa abordagem, a Política Nacional de Atenção à Saúde dos Povos Indígenas (PNASPI) adota normativamente a proposta de atenção diferenciada, que consiste na articulação entre os saberes e práticas autóctones com os do modelo biomédico, respeitando as peculiaridades que determinam a paridade no diálogo entre ambos os sistemas terapêuticos (BRASIL, 2002).

Acreditamos, portanto, que a transformação dos sistemas de saúde deve levar em conta a valorização dos segmentos organizacionais não constituídos 
no processo de institucionalização de novas formas de se produzir saúde, pois

não se deve encarar a institucionalização em saúde com o objetivo de torná-la parte da norma, mas como um processo dinâmico de construção social que se enriquece e se transforma historicamente de acordo com a visão de mundo de seus idealizadores e dos determinantes do contexto no qual se inserem. No mais, faz-se necessário criar mecanismos eficazes de avaliação dos serviços prestados que partam de marcos conceituais distintos e permitam construir cogestores desses serviços, visto que a institucionalização das práticas assistenciais constitui um processo histórico e social, concretamente povoado por atores que disputam interesses muitas vezes conflitantes e divergentes (LINS; CECÍLIO, 2008).

Vem sendo discutida atualmente, em nível nacional, a transição do subsistema de atenção à saúde indígena para uma secretaria especial diretamente vinculada ao Ministério da Saúde. É necessário destacar, no entanto, que quaisquer que sejam as propostas existentes para a melhoria da qualidade assistencial da população indígena, elas devem levar em conta a ampla rede de influências que interferem na efetivação das políticas públicas nos âmbitos municipais, onde em muitos casos os interesses econômicos se sobrepõem ao comprometimento de gestores, técnicos e demais profissionais com a inversão do quadro histórico marcado por altos coeficientes de vulnerabilidade aos agravos à saúde desta população.

\section{Conclusão}

Através do presente artigo, buscou-se dar visibilidade aos múltiplos problemas que emergem das tensões subjacentes aos relacionamentos interculturais entre os Guarani Mbyá do Espírito Santo e os representantes das instituições públicas de saúde com as quais se relacionam. A referência da interculturalidade como parâmetro avaliativo das relações estipuladas no âmbito cotidiano, político, normativo e axiológico, serviu como guia para a compreensão não somente de como os índios dialogam com os valores, tecnologias e práticas do modelo biomédico de saúde, mas também para o conhecimento dos limites que se colocam como barreiras ao acolhimento do outro como sujeito do cuidado e do co-gerenciamento das atividades desenvolvidas.

No mundo atual, a globalização tem criado meios, cada vez mais heterogêneos, tornando inevitável a construção de políticas públicas que deem conta de assegurar o reconhecimento da igualdade de direitos de expressão cultural nos âmbitos sociais, 
institucionais e jurídicos, em detrimento da neutralidade axiológica que permeou historicamente as ideologias universalizantes e homogeneizadoras da sociedade brasileira. Contudo, através desta pesquisa ficou patente que, no caso específico dos Guarani Mbyá de Aracruz, Espírito Santo, o exercício das propostas políticonormativas costuma sofrer influências dos interesses econômicos transnacionais que se sobrepõem em várias esferas da vida cotidiana àqueles indispensáveis à qualificação dos serviços de promoção, proteção e recuperação da saúde indígena.

A utilização do conceito de signo ideológico possibilitou compreender que os espaços públicos com os quais os Mbyá de Aracruz se relacionam evidenciamse como campos de expressão hierárquica de poder, onde os coeficientes de autonomia dos sujeitos são demarcados em função da supremacia dos interesses empresariais que se infiltram em todas as esferas da vida cotidiana da região. Por fim, vale destacar que, ao pensarem as múltiplas possibilidades a serem alcançadas através da coconstrução de modelos institucionais capazes de ofertar serviços que atendam as suas reais necessidades, os Guarani Mbyá o fazem retomando empiricamente os elementos constitutivos do conceito ampliado de saúde que tanto inspirou a idealização de um sistema sanitário pautado nos princípios da equidade, universalidade e integralidade da assistência e construído com ampla participação e controle social.

\section{Referências}

BAKHTIN, M. Marxismo e Filosofia da linguagem: problemas fundamentais do método sociológico da linguagem. 12. ed. São Paulo: Hucitec, 2006.

BARTH, F. Grupos étnicos e suas fronteiras. São Paulo: Unesp, 1998.

BERTOLANI, M.N. Representaçôes sociais da saúde e políticas de saúde voltadas a populaçôes indígenas: uma análise da relação entre o sistema de saúde guarani e a biomedicina. 2008. 195 p. Dissertação (Mestrado em Política Social) - Universidade Federal do Espírito Santo, Vitória, 2008.

BRASIL. Fundação Nacional de Saúde. Política Nacional de Atenção à Saúde dos Povos Indígenas. Brasília: Fundação Nacional de Saúde, 2002.

Ministério da Saúde. Portaria MS no 2656/2007. Disponível em: <http://www. funasa.gov.br/internet/portarias_Ministeriais.asp>. Acesso em: 14 de jun. 2008.

BUSS, P.M. Uma introdução ao conceito de promoção de saúde. In: COSTA, D.C. (Org.). Promoção de saúde: conceitos, reflexões e tendências. Rio de Janeiro: Fiocruz, 2003. p. 15-38. 
CAMPOS, G.V.S.; CAMPOS, R.T.O. Co-construção de autonomia: o sujeito em questão. In: et al. (Org.). Tratado de saúde coletiva. São Paulo: Hucitec, 2006. p. 669-688.

CANCLINI, N.C. Diferentes, desiguais e desconectados: mapas da interculturalidade. Rio de Janeiro: Editora UFRJ, 2005.

CICCARONE, C. Drama e sensibilidade: migração, xamanismo e mulheres mbya guarani. 2001. 382 p. Tese (Doutorado em Ciências Sociais) - Pontifícia Universidade Católica de São Paulo, São Paulo, 2001.

COIMBRA JR., C.E.A; SANTOS, R.V. Saúde, minorias e desigualdade: algumas teias de inter-relações, com ênfase nos povos indígenas no Brasil. Ciência \& Saúde Coletiva, Rio de Janeiro, v. 5, n. 1, p. 125-132, 2000.

CONFALONIERI, U.E.C. Saúde das populaçôes indígenas. Uma introdução para profissionais de saúde. Rio de Janeiro: ENSP/Fiocruz, 1993.

CUCHE, D. A noção da cultura nas ciências sociais. Bauru: EDUSC, 2002.

FREIRE, J.R.B. A representação da escola em um mito indígena. Revista Teias, Rio de Janeiro, v. 3, p. 113-120, 2001.

GARNELO, L. Política de saúde dos povos indígenas no Brasil: uma análise situacional do período de 1990 a 2004. .In: XXVIII Reuniāo da ANPOCS, 2004, Caxambu. Anais... Caxambu: ANPOCS, 2004. p. 1-28.

LINS, A.M.; CECILIO, L.C.O. O discurso da institucionalização de práticas em saúde: uma reflexão à luz dos referenciais teóricos das ciências humanas. Physis, Rio de Janeiro, v. 18, n. 3, p. 483-499, 2008.

LUZ, M.T. Cultura contemporânea e medicinas alternativas: novos paradigmas em saúde no fim do século XX. Physis, Rio de Janeiro, v. 15, supl., p. 144-176, 2005.

ORGANIZAÇÃO INTERNACIONAL DO TRABALHO. Convenção 169. 1989. Seção Direitos Internacionais. Disponível em: <http://www.socioambiental.org>. Acesso em: 03 de mai. 2006.

ORGANIZACIÓN MUNDIAL DE SALUD. Organización Panamericana de la Salud. Incorporación del enfoque intercultural de la salud en la formación y desarrollo de recursos humanos. Washington DC, 1998.74 p.

PELLON, L.H.C. Saúde Guarani: uma abordagem antropológica. 2005. 81 p. Trabalho de conclusão de curso (Graduação em Enfermagem). Escola de Enfermagem Luiza de Marillac, Rio de Janeiro, 2005.

SABÓIA, V.M. Educação em saúde: a arte de talhar pedras. Niterói: Intertexto, 2003.

SCLIAR, M. História do conceito de saúde. Physis, Rio de Janeiro, v. 17, n. 1, p. 29-41, 2007. SOUZA, S.J. Infância e linguagem: Bakhtin, Vigotsky e Benjamin. 6. ed. Campinas: Papirus, 2001. 
TURATO, E.R. Tratado da metodologia da pesquisa clínico-qualitativa: construção teóricoepistemológica, discussão comparada e aplicação nas áreas da saúde e humanas. Petrópolis: Vozes, 2003.

VEIGA, F.B. (Org.). Estudo antropológico sobre as terras e populações indígenas de AracruzES. Rio de Janeiro: Petrobras/Biodinâmica, 2004. CD-ROM.

\section{Notas}

${ }^{1}$ Desde 1967, a atenção à saúde indígena vinha sendo desenvolvida pela Fundação Nacional do Índio, órgão vinculado ao Ministério da Justiça que, por sua vez, herdou esta responsabilidade do Serviço de Proteção aos Índios, órgão do Ministério da Agricultura que desenvolveu o primeiro modelo de assistência à saúde indígena a partir da década de 1950 .

${ }^{2}$ Artigos no 231 e no 232.

${ }^{3}$ As bases legais que regulamentam a Atenção à Saúde Indígena são descritas na Lei no 9836/1999, no Decreto no 3156/1999, nas Portarias no 1163/1999 do Ministério da Saúde e nas Portarias Ministeriais $\mathrm{n}^{\circ} 069$ e $070 / \mathrm{GM}$.

${ }^{4}$ A situação fundiária foi regularizada a partir da publicação da Portaria MJ no 1.463, de 27 de agosto de 2007, após a área em questão ser reconhecida por quatro Grupos de Trabalho da Fundação Nacional do Índio (FUNAI) como de ocupação tradicional dos povos indígenas do Espírito Santo. 
Culture, intercultural relations and the healthdisease process: healthcare ways among the Guarani Mbya from the city of Aracruz, State of Espirito Santo

This paper arises as a way of systematizing the reflections based on the "Intercultural tensions and the impacts on the health-disease process in the Guarani Mbyá from the city of Aracruz, State of Espírito Santo, approached by its authors, under a process for knowledge development within the Post-graduation on NUrsery at Rio de Janeiro Federal University (UniRio). The paper aims to stimulate a reflection about the contradictions arising from the health politics for indigenous populations in Brazil, whose guidelines do not contribute for the construction of new approaches that raise the value of diversity in the ethnical and cultural viewpoints. Its approach can be classified as descriptive with qualitative approach of a study case. Data were collected from semi-structured interviews conducted together with members of the Mbyá, Aracruz, Espírito Santo, and its analysis was based on the rules that subsidize indigenous healthcare actions. The conclusion is indigenous healthcare is influenced by local, regional and global political, economic and social interests, that, in many respects, overlap or neglect those aspects so necessary for the promotion and protection on the quality of life of the Mbyá groups living in Aracruz.

> Key words: nursing; health-disease; indigenous health; health policies. 